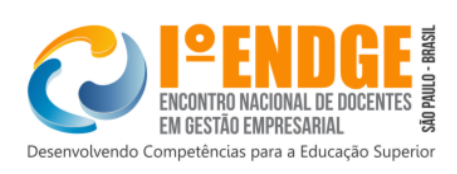

Área temática: Empreendedorismo

\title{
Práticas de docência orientadas para a inovação e empreendedorismo: análise sob as práticas e perspectivas dos docentes de Administração da UNIJUÍ
}

\author{
Rúbia Goi Becker - rubia.goi@ unijui.edu.br \\ Universidade Regional do Rio Grande do Sul - UNIJUÍ \\ Gustavo Arno Drews - gadrewes@unijui.edu.br \\ Universidade Regional do Rio Grande do Sul - UNIJUÍ
}

\begin{abstract}
Resumo
As Instituições de Ensino Superior, como geradoras e disseminadoras de conhecimento, constituem-se como potenciais agentes das práticas de desenvolvimento e fomento da inovação e empreendedorismo. É evidente a importância das ações efetivas que devem ser realizadas no âmbito universitário, considerando o fato de que a sociedade espera encontrar as respostas para as questões pertinentes ao desenvolvimento das regiões e do país. A cultura do empreender nas bases de formação do ensino superior surge como primeiro passo na formação do perfil empreendedor, o que leva este artigo a identificar o uso de práticas docentes orientadas para o empreendedorismo e inovação, aplicadas no Curso de Bacharelado em Administração da UNIJUÍ, sob a perspectiva de docentes e discentes. Estas práticas atuam como diferenciais de formação acadêmica, agindo como catalisador no processo de formação de empreendedores, seja pelo suporte da estrutura universitária, pelas bases pedagógicas ou pela metodologia de ensino adotada pelo corpo docente.
\end{abstract}

Palavras chave: Inovação; Empreendedorismo; Práticas de Docência

\begin{abstract}
Higher education institutions, such as generators and disseminators of knowledge, constitute as potential agents of development practices and promote innovation and entrepreneurship. Clearly the importance of effective action to be carried out in universities, considering the fact that the company hopes to find the answers to the questions relevant to the development of regions and the country. The undertaking of culture in higher education training bases comes as a first step in the formation of entrepreneurial profile, which leads this article to identify the use of teaching practices geared towards entrepreneurship and innovation, applied in Administration Bachelor Degree Course UNIJUÍ, from the perspective of teachers and students. These practices act as academic differences, acting as a catalyst in the formation of entrepreneurs process, is the support of the university structure, the teaching bases or the teaching methodology adopted by the faculty.
\end{abstract}

Key words: Innovation; Entrepreneurship; Practice Teaching 


\section{INTRODUÇÃO}

As orientações do atual modelo de organização capitalista vêm impondo novas demandas aos indivíduos, sociedades, Estados e Governos, particularmente no campo educacional. A sociedade passa a ser guiada pelo capital do conhecimento, movida pela tecnologia da informação, fatores que aliados a atitudes, competências e habilidades norteiam a construção de um comportamento empreendedor, que por sua vez, envolve a geração de iniciativas e ações inovadoras e criativas, que tenham utilidade e importância ao mercado consumidor.

O cenário de tendências indica que a vida neste século será pautada pela educação continuada, pela criatividade, pela inovação e pelo empreendedorismo em todas as áreas e dimensões da vida humana, individual e coletiva. É possível perceber que os comportamentos mudaram e mais do que aprender sobre o novo, os profissionais precisam aprender a reciclar saberes. Esta situação motiva o desafio de preparar e desenvolver o jovem acadêmico por meio da formação profissional que o prepara para atender a esta demanda. Porém, para isso necessitase definir e delimitar os responsáveis por essa internacionalização de conceitos e práticas, formando um ambiente propício para a aplicação da cultura empreendedora e de inovação.

Para Dolabela (2003, p.26) "a pedagogia Empreendedora toma o empreendedor como alguém capaz de gerar novos conhecimentos a partir de uma dada plataforma, constituída por 'saberes' acumulados na história de vida do indivíduo e que são os chamados "quatro pilares da educação' - aprender, a saber, aprender a fazer, aprender a conviver e aprender a ser". É característico do perfil empreendedor criar e alocar valores para indivíduos e para a sociedade, sendo o grande provedor de inovação tecnológica e crescimento econômico.

Assim como o empreendedorismo, a inovação é decorrente de um estado de espírito, é o comportamento de deixar de querer para passar ao fazer. Lopes (2010) aponta que para facilitar a mudança e o desenvolvimento em um determinado contexto é necessário que haja inovação, representando o fator mais importante de crescimento e alavancagem econômica, não apenas no desenvolvimento de produtos e serviços, mas especialmente no estímulo ao interesse em investir em novos empreendimentos que estão sendo criados. A universidade, como forma de organização, tem responsabilidade e atuação em relação ao desenvolvimento social e econômico, considerando principalmente seu ambiente fomentador e propulsor para $\mathrm{o}$ desenvolvimento das capacidades empreendedoras e de projetos de pesquisa voltados a inovação.

Segundo Lopes (2010, p. 129-127), a Educação Empreendedora "advém dos termos em inglês entrepreneurship education e enterprise education". O termo remete a programas de formação de empreendedores que objetiva a criação de um entendimento e talvez a motivação no sentido da criação do próprio negócio. Portanto, o desenvolvimento de habilidades e conhecimentos técnicos orientados para o negócio que visem lucro financeiro; e os programas de enterprise education buscam desenvolver as habilidades e os atributos de um indivíduo empreendedor e não apenas a motivação para negócios que visem lucros.

Diversos governos estão demonstrando um maior interesse na promoção do empreendedorismo. As pessoas são estimuladas a formar novas empresas e recebem apoio governamental, como vantagem nos impostos, prédios, terrenos, estradas e sistemas de comunicação para facilitar o processo de criação. Esses incentivos devem ser adotados por um maior número de governos, à medida que mais legisladores compreenderem que novas empresas geram empregos e aumentam a produção econômica na região. A aliança tríplice fornece sustentação a geração de um ambiente propício à inovação, através de alianças estratégicas entre empresas e universidades apoiadas por iniciativas governamentais, combinando iniciativas de atuação em conjunto.

É neste ambiente que o meio acadêmico passa a ser reconhecido como um agente de transformação empreendedora, promovendo iniciativas estimulantes ao exercício de empreender, criando condições para a capacitação profissional dos acadêmicos, aprimorando o desempenho institucional e contribuindo ao desenvolvimento econômico-social local e regional. Diante de tais considerações, definiram-se os seguintes objetivos específicos: (i) conhecer a 


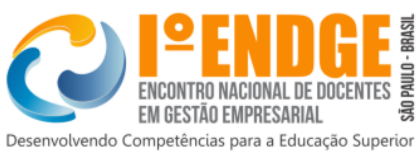

percepção de uma amostra de docentes do curso de Administração da UNIJUí sobre dos conceitos de Educação Empreendedora e as respectivas metodologias de ensino e aprendizagem que adotam na docência orientada à formação de competências de inovação e empreendedorismo, apresentando um quadro descritivo destas práticas; (ii) conhecer a percepção de alunos do curso de Administração quanto às práticas de docência desenvolvidas pelos professores; (iii) conhecer o PPC do curso na leitura e estudo do mesmo; (iv) comparar essas três bases de dados, analisando-as à luz do modelo da Tríplice Hélice; (v) propor subsídios aos coordenadores e docentes para reflexões acerca do tema com vistas à formulação de ações de manutenção ou ajustes se necessário.

Ao se buscar atingir tais objetivos, chegou-se à principal questão de pesquisa do estudo: "Quais as práticas de docência, orientadas para a inovação e empreendedorismo, são desenvolvidas no curso de Administração da Universidade Regional do Rio Grande do Sul - UNIJUÍ"? Esse problema desencadeou o objetivo central do trabalho, que é verificar as práticas de docência orientadas para o viés da inovação e empreendedorismo, que são desenvolvidas no curso de Administração da Universidade Regional do Rio Grande do Sul UNIJUÍ. O alcance dos objetivos secundários é fundamental para dar base à consecução do objetivo principal.

Baseado neste discurso, a importância de estudar recai sobre seis esferas: à UNIJUÍ, ao curso de Administração, aos professores de Administração, aos acadêmicos de Administração, às empresas e o governo. Para a UNIJUÍ este estudo fornece subsídios para o seu planejamento estratégico, oferecendo informações e dados advindos da análise das práticas de docência realizadas no Curso de Administração no viés do empreendedorismo e inovação, sob a percepção de docentes e acadêmicos, com embasamento técnico/teórico para a comparação e avaliação interna e externa do diferencial em qualidade de ensino que o curso apresenta.

Para o curso de Administração este estudo vem contribuir para a excelência do mesmo, possibilitando a avaliação entre o que o curso propõe, em quesitos de excelência em formação profissional, e o que vem sendo feito em termos de qualificação e renovação técnica para a equipe de docentes. Aos professores, o estudo proporciona uma avaliação dos procedimentos metodológicos utilizados sob dois ângulos: a comparação com os estudos já desenvolvidos sobre as práticas de ensino do empreendedorismo e inovação; e sobre a percepção dos acadêmicos quanto às práticas mantidas até o momento, apontando quais são efetivas e as que necessitam ser aprimoradas ou implantadas. Aos alunos o estudo conduz a alternativas de aumento na qualidade de ensino e melhoria no diferencial da formação profissional destes, através de metodologias e práticas que devem ser mantidas e/ou implementadas para que ocorra o atingimento dos objetivos estabelecidos no Projeto Pedagógico do Curso (PPC).

A importância do estudo também estende-se para o meio empresarial, um dos maiores interessados na formação de profissionais competentes, resilientes e dinâmicos (características do perfil empreendedor). O âmbito governamental também será beneficiado, uma vez que se reconhece o fato de ser a atitude empreendedora capaz de gerar transformações importantes nos diversos segmentos da economia, possibilitando abrir novos campos de estudo que se complementarão com os que já existem até o momento, gerando conhecimento agregado e subsídios para a formação de profissionais capacitados e qualificados, que poderão suprir a demanda por profissionais nas empresas e a geração de novos negócios.

Para atingir os objetivos propostos, o trabalho estrutura-se da seguinte maneira: na seção 2, são discutidos aspectos teóricos relativos à empreendedorismo e inovação; na seção 3, são apresentados as faces do Empreendedorismos no Brasil; na seção 4, são abordados os elementos de formação do comportamento empreendedor; na seção 5, é descrito o caminho metodológico adotado neste estudo; na seção 6, são apresentados os resultados encontrados, bem como as bases de um modelo proposto e os eixos e estratégias do mesmo. Para finalizar, na seção 7, são apresentadas as considerações finais acerca do trabalho desenvolvido.

\section{Empreendedorismo, inovação e educação empreendedora 2.1 Empreendedorismo e Inovação}




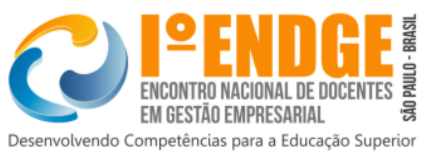

A natureza da palavra empreendedorismo é francesa, entrepreuner, literalmente traduzida, significa "aquele que está entre" ou "intermediário". Na Idade Média o termo empreendedor foi usado para descrever tanto um participante quanto um administrador de grandes projetos de produção. Nesses projetos, esse indivíduo não corria riscos: simplesmente administrava o projeto usando os recursos fornecidos, geralmente pelo governo do país (HISRICH; PETERS; SHEPHER, 2009, p. 27-28, apud Dolabela, 2008, p.60).

Dolabela (2008, p. 59) ainda salienta os estudos de Jean-Baptiste Say (1964), considerado pai do empreendedorismo, e o economista austríaco Schumpeter (1934), o qual relançou as ideias sobre o empreendedor e seu papel na sociedade, associam o empreendedor ao desenvolvimento econômico, a inovação e ao aproveitamento de oportunidades de negócios. De acordo com os estudos de Dolabela (2008, p. 60) pode-se dizer que o indivíduo empreendedor "é aquele que se dedica à geração de riquezas, seja por meio da transformação de conhecimentos em produtos ou serviços, na geração do próprio conhecimento ou na inovação nas diversas áreas existentes na organização".

Para Lopes (2010, p. 18) "muitos fatores contribuem para o surgimento do empreendedor: personalidade, família, etnia, cultura, religião, exposição a negócios, modelos, experiências de trabalho". Nesta conjuntura, a educação e o desenvolvimento/treinamento possuem papel decisivo no encorajamento do empreendedorismo, ao ponto que desenvolvem atitudes, conhecimentos e habilidades. Para desenvolver a iniciativa, criatividade e inovação requer-se que o empreendedor seja capaz de gerir uma organização, o que demanda habilidades gerenciais afim de garantir resultados positivos e eficazes. Fontenele (1994 apud Timmons, 1990) salienta em seu blog uma das frases mais famosas de Jeffry Timmons, "o empreendedorismo é uma revolução silenciosa, que será para o século XXI mais do que a revolução industrial foi para o século XX."

A inovação por sua vez surge como meio de geração de valor e sustentabilidade do negócio. É um tema que se disseminou rapidamente nos últimos anos e hoje está presente na pauta das discussões estratégicas de grande parte das empresas, no Brasil e no mundo. Derivado do termo em latim innovare, inovar significa tornar algo novo. Nos últimos anos, a inovação tem se estabelecido como um dos fatores importantes para garantir o crescimento, a competitividade e a rentabilidade diferenciada às empresas.

A importância do conceito de indivíduo empreendedor e inovador está na sobrevivência dos empreendimentos, além corroborar na diferenciação do profissional no mercado de trabalho. A própria economia globalizada do século XXI, remete a inovação como fator fundamental de competitividade, diante do panorama de concorrência mundial. A inovação apresenta especial relevância na economia contemporânea quando se manifesta na figura da propriedade intelectual, definida em termos genéricos como um direito concedido pelo estado que visa proteger a exploração econômica de qualquer produção do intelecto.

Tempos atrás, o termo inovação era visto como inventar algo novo, o pensamento atual, contudo considera a inovação como um meio para criar valor com base em enfoques que estimulam novas formas de operar em todo o sistema. De modo geral, a inovação é uma atividade social que promove ideias novas e úteis. Implicam em repetição, avanço e participação de indivíduos diferentes, que podem surgir em períodos divergentes. Dolabela (2008) ainda destaca o estudo sistemático da inovação é relativamente recente, onde novamente Schumpeter (1883 - 1950), frequentemente considerado o precursor do estudo da inovação através de sua obra Teoria do Desenvolvimento Econômico, publicada em 1912.

\subsection{Empreendedorismo no Brasil}

No Brasil, pode-se dizer que a Educação Empreendedora está em fase inicial de implementação, no entanto os resultados alcançados no ensino indicam o início de uma revolução silenciosa. A atividade empreendedora ainda não é reconhecida pela sociedade de forma inteiramente positiva, pois para o senso comum da maioria, o empresário brasileiro parece ser visto como o dono de uma grande empresa e não como o indivíduo que tem uma boa ideia e implanta seu próprio negócio. Esta percepção negativa acarreta a tímida implementação 


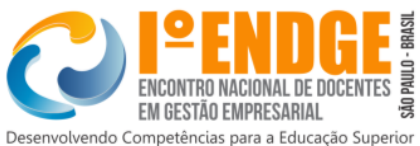

da cultura empreendedora, que em outras circunstâncias iria por si própria impulsionar e difundir a educação empreendedora.

A prática do empreendedorismo mostra-se cada vez mais frequente no Brasil como opção de carreira, frente às dificuldades sócio-econômicas que assolam o país e reduzem as oportunidades para aqueles que querem ingressar no mercado de trabalho. Segundo Bandeira (2011), em matéria publicada pela Revista Administradores sobre os dados da pesquisa elaborada pela Global Entrepreneurship Monitor (GEM), sobre o Empreendedorismo no Brasil;

O Brasil tem a maior taxa de empreendedores iniciantes do $\mathrm{G}_{20}$ - Grupo das 20 maiores economias do mundo - e do BRICS - reunião dos países emergentes formado por Brasil, Rússia, Índia, China e África do Sul. Em números isso significa que em 2010, ano base do levantamento, 21,1 milhões de brasileiros eram empreendedores em negócios com até três anos de atividade, ficando atrás apenas dos chineses. (BANDEIRA 2011, p. 15)

A pesquisa também apontou que "[...] o empreendedorismo no Brasil tem sido motivado mais por oportunidade do que por necessidade (casos em que se empreende por não haver alternativa) - o que pelo menos teoricamente indica uma atividade mais qualificada". Bandeira (2011) faz referência aos dados do indicador do Serasa Experian de Falências e Recuperações, o qual "registrou, em janeiro o menor índice de pedidos de falência em um início de ano desde 2005, embora o número ainda continue alto". Ainda segundo o autor, com base nos dados do Banco Mundial, "o Brasil ocupa a posição de $127^{\mathrm{a}}$ posição no ranking de facilidades de efetivar negócios, fator que repercute a burocratização excessiva, a alta carga tributária e a infraestrutura incipiente."

Já com o incentivo nos estudos e formação de profissionais voltado para o empreendedorismo, o governo brasileiro tem focado na cultura empreendedora, a exemplo de outros países, em que já existem projetos para educação e incentivo à cultura empreendedora ainda no ensino fundamental, o que é muito bom para os países em época de crise, pois uma vez que essa cultura está enraizada, um cidadão que se encontra desempregado, saberia utilizar de outras formas para prover o seu sustento.

A disseminação da cultura empreendedora e a aceitação do empreendedorismo pela população contribuem para o desenvolvimento da capacidade empreendedora, considerando a aproximação do empreendedorismo ao cotidiano da população. Por outro lado, a baixa escolaridade e a falta de foco no momento de empreender podem limitar esse processo. $\mathrm{Na}$ opinião de especialistas na área a falta de planejamento e deficiência na gestão dos empreendimentos, são os principais fatores para o insucesso dos negócios, principalmente nos primeiros anos de atividade, e até pelo baixo potencial de crescimento.

Para lidar com tais variáveis do ambiente, o conhecimento técnico do negócio é importantíssimo, mas não assegura o sucesso do mesmo, pois as características pessoais de persistência, ousadia, relacionamento, criatividade, inovação, coragem para correr riscos, identificar oportunidades, visão para saber qual a direção a seguir e principalmente ter paixão pelo que faz são as grandes impulsionadoras de organizações de sucesso.

O empreendedorismo é importante e essencial para a economia de um País, Estado e Município, pois o surgimento de novas empresas proporciona aumento na geração de renda, emprego fazendo com que circule mais dinheiro no comércio local.

\subsection{Formação do Comportamento Empreendedor}

O Instituto Euvaldo Lodi (2000) trabalha toda a história e progresso da Educação Empreendedora no Brasil. O primeiro curso na área de empreendedorismo que se tem notícia surgiu em 1981, na Escola de Administração de Empresas da Fundação Getúlio Vargas, São Paulo, por iniciativa do professor Ronald Degen, e se chamava "Novos Negócios". Era uma disciplina do Curso de Especialização em Administração para Graduados (CEAG). Em 1984, o curso foi estendido para a graduação, sob o nome de "Criação de Novos Negócios - Formação 
de Empreendedores", e hoje é uma das "trilhas" obrigatórias a serem percorridas pelos alunos em diversas Instituições de Ensino.

Lopes (2010, pag. 22) salienta que "especialistas europeus concordam e reconhecem que a escola pode incentivar o desenvolvimento das habilidades empreendedoras entre os alunos, desde cedo. Indicam ainda que se deve desenvolver as habilidades e técnicas e de negócios entre aqueles que preferirem ter seu auto emprego ou criar seu próprio negócio, no presente ou no futuro". Para Mintzberg (2000);

A escola empreendedora [...] não só focalizou o processo de formação de estratégia exclusivamente no líder único, mas também enfatizou o mais inato dos estados e processos - intuição, julgamento, sabedoria, experiência, critério. Isto promove uma visão da estratégia como perspectiva, associada com imagem e senso de direção, isto é visão. (MINTZBERG 2000, p.98 apud Lopes, 2010).

O tema "ensino de empreendedorismo" está ligado às novas formas de aprendizado e relacionamento, em virtude dos fundamentos que defendem o ideal de empreendedor não serem somente uma questão de acúmulo de conhecimento, mas indispensavelmente ser o indivíduo dotado de valores, atitudes, comportamentos, percepções de mundo e de si mesmo voltados para atividades em que o risco, a capacidade de inovar e de conviver com a incerteza são elementos indispensáveis. Assim, a academia deve representar um campo extremamente pragmático, formadora de um ambiente propício ao desenvolvimento do ensino de empreendedorismo através de docentes qualificados, projetos de extensão voltados para a pesquisa e inovação, disponibilizando incubadoras e parques tecnológicos.

O desafio do profissional docente reside em estimular, desenvolver e fomentar o pensamento criativo e inovador, dado que não se equaciona facilmente como ensiná-lo/inseri-lo no contexto da educação/treinamento. Esse pressuposto é desafiado e fortalecido na própria experiência prática, no contexto e no ambiente de negócios, ao induzir o acadêmico a interagir com problemas, situações e pessoas. Conforme Lopes (2010):

Para desenvolver as capacidades que permeiam o indivíduo empreendedor o docente deverá dotar-se de algumas práticas e processo de aprendizagem, como: a) Workshops e discussões em grandes grupos; b) revisões críticas; c) apresentações; d) ensino em pares; e) aconselhamento em pares; f) resolução de problemas reais; g) simulação de resolução de problemas; h) debates; i) estudo de casos; j) uso de incidentes críticos; $k$ ) enfoques de consultorias e aconselhamento (coaching); 1) aprendizagem por experiências; m) brain storming; n) aprendizagem investigativa; o) vídeo interativo; p) aprendizagem baseada em informática; q) seminários; r) aulas expositivas; s) apostilas, livros textos etc. (LOPES; 2010, p. 139).

O papel da IES - Instituições de Ensino - é viabilizar a implementação de projetos bem analisados e fundamentados, através de orientação, consultoria, empréstimos especiais, e facilidades para o negócio, dando suporte para ideias, desde seu embrião até a etapa de nascimento dos novos empreendimentos, fazendo uma ponte entre poder público e empresas privadas. Neste ponto encontra-se outro conceito, definido como "Tríplice Hélice" o qual representa a relação de troca mútua entre o sistema de educação, as políticas governamentais e geração de produtos (bens e serviços) por parte das empresas. Esses três alicerces devem andar juntos, a fim de criar um ambiente propício ao desenvolvimento e sustentabilidade de uma região ou país.

Neste contexto, percebe-se forte ligação entre o conceito de Tríplice Hélice e Parques Tecnológicos, que segundo Lopes (2010) compreendem: Empreendimentos que têm como propósito a interação entre Universidade, Empresas e Governo em uma área física delimitada e especialmente destinada ao desenvolvimento de projetos de Pesquisa e Desenvolvimento 


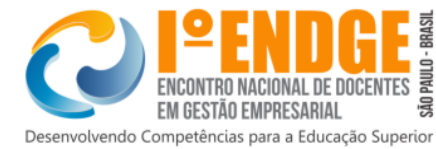

(P\&D). Estes empreendimentos são considerados por esses autores como "instrumentos de desenvolvimento científico, tecnológico, de inovação e de geração de empregos e renda".

A partir desta conotação tem-se uma linha de pensamento interligada, exigindo necessidade de se ter uma sinergia entre os atores desses cenários que estimulem o desenvolvimento econômico e social das comunidades na qual estão inseridos, fomentando a produção científica e tecnológica e a inovação. É um ecossistema que tem um ciclo completo entre os envolvidos, um cenário onde novas formas e modelos de desenvolvimento emergem. Toda intenção de implantação e evolução de programas de educação empreendedora em instituições de ensino superior se sustenta a partir do objeto gerar reflexão e análise acerca do tema empreender, buscando desenvolver indivíduos de forma consciente e engrandecedora, respeitando as diversas maneiras e formas de aprender.

\section{Metodologia}

Para efetuar o estudo, adotaram-se os procedimentos metodológicos propostos por Vergara (2004) e Gil (2010), classificando a pesquisa quanto aos fins e aos meios. A pesquisa foi classificada como exploratória e descritiva. A pesquisa quanto aos seus procedimentos técnicos foi caracterizada como bibliográfica, documental, pesquisa de campo e pesquisa participante. Visando dar forma ao tema proposto e com a finalidade de obter resposta aos objetivos especificados, decidiu-se por fazer uma pesquisa de campo sobre as práticas de docências desenvolvidas no curso de Administração no viés do empreendedorismo e inovação. Os sujeitos de pesquisa foram os docentes do curso de Administração, os acadêmicos presentes nos períodos entre o quarto ao décimo semestre e a própria autora enquanto sujeito participante. Foram realizadas 24 entrevistas com docentes e aplicados 147 questionários aos acadêmicos entre o período de fevereiro e março de 2014. Com a aplicação dos questionários pela autora, os dados foram tabulados e dispostos através de tabelas com percentuais.

\section{ANÁLISE DOS RESULTADOS}

Foram pesquisados 147 acadêmicos entre o $4^{\mathrm{a}}$ e o $10^{\mathrm{a}}$ semestres da graduação e 24 docentes do curso de Administração. Em síntese, a partir do estudo e análise do perfil dos acadêmicos, pode-se definir um panorama de jovens profissionais, em maioria expressiva do sexo feminino (64\%), ativos no mercado de trabalho e ocupando cargos de início de carreira, com a maioria apresentando até um ano de empresa e cargo, o que pode remeter a atuação do profissional em início de carreira se considerar à faixa etária de até 23 anos (56\%) predominante entre os pesquisados.

Em relação ao perfil da amostra de docentes pesquisada, tem-se destaque ao Curso de Administração da UNIJUÍ estar composto, em sua maioria, por um quadro docente qualificado, apresentando profissionais com longa experiência em docência, possuindo graduação de Bacharelado em Administração e titulação de mestre. Aponta-se também a importância da experiência junto ao meio organizacional, uma vez que esta aproxima o ensino conteudista da prática vivenciada, o que pode motivar e influir no desenvolvimento do instinto empreendedor entre os acadêmicos.

Sobre a análise das práticas de docência orientadas ao empreendedorismo e inovação, observa-se que apesar de docentes e discentes terem apontado conceitos como Inovação, Criatividade, Conhecimento, Atitude, Dinamismo, Planejamento e Visão Sistêmica para definir Educação Empreendedora, não esgota-se aqui esta definição, visto que o parâmetro utilizado diferente de acordo com a percepção e opinião de cada docentes e discentes. Há de se considerar que por tratar-se de um tema complexo, que pressupõem variações de análises, de maneira a envolver uma aliança de outros conceitos, a Educação Empreendedora visa desenvolver o perfil 
empreendedor, as atitudes, competências e comportamentos necessários ao indivíduo empreendedor.

O estudo apontou um percentual considerável de discentes não convergem com a utilização de metodologias que fazem referência a educação empreendedora dinamizando o aprendizado e facilitando a compreensão entre teoria e prática, assim como também não convergem com o reconhecimento da proposta do curso no decorrer das disciplinas, posicionamento que se contradiz ao ponto que apontam a existência de técnicas utilizadas pelos professores para dinamizar o aprendizado e facilitar a compreensão entre teoria e prática.

Percebe-se uma situação de dubiedade remetida ao percentual de $21 \%$ da amostra de acadêmicos que não se manifestou convergente ou contrária, em que muitos dos acadêmicos encontram-se duvidosos quanto à efetividade ou entendimento da realização de metodologias voltadas à educação do empreendedor e em relação a proposta do curso difundida e explicita nas disciplinas que compreendem o curso, fazendo-se referência a Educação Empreendedora. Contudo, a existência de ações para difusão da Educação Empreendedora no Curso de Administração, através do que apontou as percepções de alunos e professores, confirma-se. $\mathrm{O}$ percentual da amostra que discorda da existência das ações relacionadas a Educação Empreendedora no trabalho dos docentes e na proposta do próprio curso pode ser considerado pouco expressivo comparado ao percentual convergente. Em relação ao posicionamento duvidoso dos acadêmicos, o estudo não permite fazer nenhuma constatação, pois necessita-se de novos estudos aprofundados e direcionados a esta questão.

Ao partir para análise dos conteúdos e metodologias, tem-se um panorama positivo, uma vez que $100 \%$ dos docentes apontaram realizar a interrelação entre os conteúdos das disciplinas ministradas confirmando-se com a perspectiva dos alunos onde $76,9 \%$ posicionaram-se convergentes a afirmação. Em termos de organização e/ou incentivo de viagens de estudos e participação de palestras/congressos junto aos alunos para melhorar o grau de entendimento sobre os temas trabalhados em sala de aula aponta-se que há um gargalo entre os acadêmicos que não identificam esta metodologia ou apontaram estar contrário/convergentes. Apesar de $79,2 \%$ dos docentes convergirem quanto à efetividade da prática o diagnóstico da pesquisa permite concluir que a mesma não tem sido efetiva a 60,5\% dos acadêmicos pesquisados, apresentando um quadro que requer avaliações mais profundas sobre a realização uniforme da prática.

Em relação aos conteúdos e metodologias adotadas o panorama é positivo, no entanto demonstra que para $25,3 \%$ dos alunos que discordam ou discordam/concordam da utilização de programas didáticos compreendendo aulas expositivas, exercícios, seminários, estudos e discussão de cases reais, interligando a disciplina com as características de empreendedorismo e inovação. Em relação aos tipos de metodologias utilizadas atualmente no curso e que dinamizam o aprendizado e facilitam a compreensão dos acadêmicos tem-se evidenciado que mesmo com um percentual menor de docentes adotando a prática de estudo e análise de cases reais, respectivamente $33,3 \%$ dos docentes, uma parcela de $70,7 \%$ dos discentes apontou esta como sendo a prática mais difundida no curso. Posteriormente estão os seminários integradores adotados por $66,7 \%$ dos docentes e evidenciado por $45,6 \%$ dos acadêmicos. Ambas as metodologias trabalham a capacidade perceptiva, comportamental e as habilidades dos acadêmicos.

Seguindo com a análise sobre o desenvolvimento de competências empreendedoras, abordando o envolvimento de docentes em projetos de pesquisa, extensão e/ou gestão mais de $80 \%$ dos docentes a tem efetivado, o que em tese valida o proposto pelo PPC (2013) que prevê a qualificação do docente acadêmica e pedagogicamente à medida que se propõem que estes se envolvam com pesquisa e extensão. Sobre a difusão das ações e projetos existentes na Universidade e que tenham relação com a disciplina cursada identificou-se uma lacuna para trabalhar-se mais a fundo esta questão entre os docentes e alunos, visto que 26,5\% dos discentes e 20,8\% dos docentes posicionaram-se de modo a não discordar e não concordar com a prática. Ao questionar docentes e discentes sobre a relevância da apresentação de comportamentos, atitudes empreendedoras e de inovação condizentes com o que o mercado procura um 


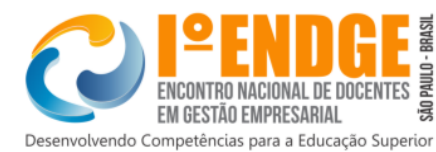

percentual positivo de $83,4 \%$ docentes e $71,4 \%$ discentes reconhecem a existência deste tipo de avaliação.

É possível reconhecer que o Curso de Administração apresenta perfil de Educação Empreendedora, considerando as grandes perspectivas que relacionam a teoria existente sobre o perfil Empreendedor nos Cursos de Ensino Superior, as diretrizes do Projeto Pedagógico do Curso de Administração da UNIJUÍ, as práticas de docência adotadas e realizadas no viés do empreendedorismo e inovação pelos docentes e a perspectiva sobre a efetividade destas pelos acadêmicos. O corpo docente do Curso de Administração da UNIJUí, em sua maioria, adota práticas de ensino do empreendedorismo, aliando os aspectos técnicos do ensino da ciência da Administração, utilizando de os princípios da Educação Empreendedora, metodologias e conteúdos voltados ao desenvolvimento do aluno empreendedor, além de relacionar em suas disciplinas aos eixos do ensino, pesquisa e extensão.

\section{Conclusão}

Diante da análise exposta, pode-se concluir que os objetivos deste estudo foram atingidos. A metodologia utilizada foi eficaz para atingir os resultados. Os roteiros de entrevistas ajudaram na identificação das percepções de docentes e acadêmicos quando as práticas de docências mantidas no Curso de Administração da UNIJUÍ no viés do empreendedorismo e inovação, realidade encontrada a campo e complementada com dados secundários, como o estudo do Projeto Pedagógico do Curso, extremamente importantes para que fosse possível confrontá-los com a realidade existente. Além do embasamento teórico que sustentou a análise dos dados.

A partir da análise e reflexão apresentadas, pode-se reconhecer a existência de práticas de docência orientadas para o empreendedorismo e inovação no Curso de Administração da UNIJUÍ. Constatou-se que os docentes vêm seguindo o PPC e tem utilizados os princípios da Educação Empreendedora para difundir o Empreendedorismo no ensino dos acadêmicos. Os alunos também validam a existência destas metodologias quando apontam alguns dos conceitos presentes na proposta da Educação Empreendedora, assim como ao reconhecer e indicar as ações e métodos adotados pelos docentes do curso de Administração. Os dados obtidos comparados com as teorias e estudos existentes sobre a temática sustentaram a conformidade da percepção dos sujeitos da pesquisa e as diretrizes e princípios do PPC do curso.

O curso de Administração da UNIJUí vem caminhando na direção da proposta de Educação Empreendedora, apresentando características e alicerces de um curso com perfil empreendedor, porém ainda a um logo caminho a ser percorrido para que esta formação seja reconhecida e identificada com clareza e consistência no curso. Uma vez que implementar os fundamentos da Educação Empreendedora remete a mudanças de comportamentos, atitudes e principalmente envolve mudança de cultura. Essa transição representa um processo lento e que precisa de alguns ajustes e alinhamentos entre a teoria, as proposições do PPC, as práticas dos docentes e a percepção dos acadêmicos. Estes fatores precisam estar combinados e alinhados para que se reconheça a efetividade da formação Empreendedora do Curso de Administração da UNIJUÍ.

Conclui-se que a universidade, no processo de difusão e fixação dos preceitos e programas de formação de empreendedores, é considerada ponto de partida na disseminação da cultura empreendedora, pois representa uma fonte multiplicadora do saber por excelência e fonte formadora de opinião. No entanto, reconhece-se como necessário disseminar a cultura empreendedora a partir do primeiro degrau do sistema educacional, nas bases do ensino fundamental. A introdução da cultura empreendedora no cerne do formação superior das Instituições de Ensino pode ser considerada como o primeiro passo na perseguição de um objetivo maior, representado pela formação de jovens empreendedores capazes de transformar a sociedade e a economia através de seu comportamento e de suas ações. Afirma-se a possibilidade de criar e difundir uma cultura empreendedora, baseada nos valores de geração e distribuição de riquezas, independência, inovação, criatividade, auto sustentabilidade, tecnologia e desenvolvimento econômico. 


\section{Referências Bibliográficas}

DOLABELA, Fernando. Pedagogia Empreendedora: O Ensino de Empreendedorismo na Educação Básica, Voltado para o Desenvolvimento Social e Sustentável. São Paulo: Editora de Cultura, 2003.

GIL, Antonio Carlos. Como Elaborar Projetos de Pesquisa. $5^{\text {a }}$ Ed. São Paulo: Atlas, 2010.

LOPES, Rose Mary A. (Org.). Educação Empreendedora: conceitos, modelos e práticas. Rio de Janeiro: Elsevier; São Paulo: Sebrae, 2010.

VERGARA, Sylvia Constant. Projetos e Relatórios de Pesquisa em Administração. 5.ed. São Paulo: Atlas, 2004. 